then a greater uniformity of growth and nutrition will be secured when the cation permeability is limited to the potassium level.

Department of Biochemistry,

EDward J. Conway.

University College,

Dublin.

March 24.

${ }^{3}$ Conway, E. J., NAture, 144, 709 (1939).

2 Boyle, P. J., and Conway, E. J., J. Physiol. (in the press, 1941).

\section{Effect of X-Rays on the Regeneration of Root Cuttings}

Roor cuttings (thongs) of seakale (Crambe maritima) are known to exhibit marked polarity. In a former communication ${ }^{1}$ a method was described of producing buds at the morphological base of a thong by periodic decapitation of both apex and base over a period of eight weeks. A working hypothesis, recently elaborated as a result of subsequent experiments ${ }^{2}$, was also outlined regarding the correlation between auxin and meristematic activity. It was suggested that relatively low and high concentrations of auxin controlled the formation of bud and root initials respectively.

A recent experiment carried out here with the use of X-rays not only adds support to this hypothesis but has also resulted in the production of buds at the base of a thong within two weeks from treatment.

Skoog ${ }^{3}$, irradiating Avena coleoptiles and solutions of heteroauxin with X-rays, claimed that the growthsubstances involved were inactivated. Since the seakale root contains auxin ${ }^{2}$, thongs were subjected to $\mathrm{X}$-rays with the intention of reducing the total amount of growth-substance in the tissues and thus preventing, as a result of polar transport, the presence of a relatively high concentration at the base.

New thongs, $8 \mathrm{~cm}$. long, cut transversely at each end were used. The parts of the thong treated with X-rays were as follows : (1) upper $3 \mathrm{~cm}$. of the thong ; (2) lower $3 \mathrm{~cm}$; (3) whole $8 \mathrm{~cm}$. Each treatment was divided into three lots and irradiated with 1,000 , 5,000 and 25,000 r-units respectively. A normal set of thongs was used as a control. Following treatment with $\mathrm{X}$-rays the thongs were incubated in sand at a temperature of $20^{\circ} \mathrm{C}$. and afterwards classified according to their appearance after eighteen days.

Control thongs produced buds at the apex and

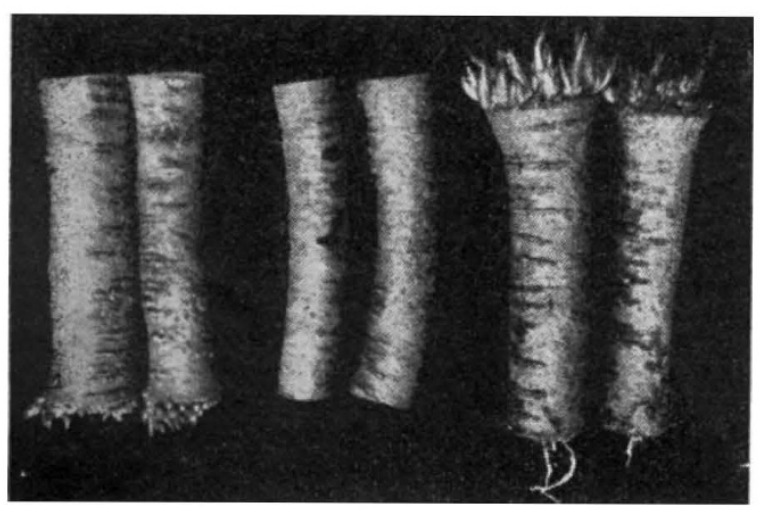

$A$

$B$

$C$

$A$, buds basally, apex inactivated. $B$, ends inactivated. $C$, normal thong. roots at the base (see accompanying figure, C). The dosage of $1,000 \mathrm{r}$-units had little effect on the regeneration of thongs in all treatments although root production was slightly decreased especially in (3). However, using concentrations of either 5,000 or $25,000 \mathrm{r}$-units, thongs receiving irradiation on the upper half produced buds at the base whilst their corresponding apices were inactivated (A); those irradiated on the lower half formed buds apically and remained inactive basally. Thongs given total irradiation remained inactive (B).

From these results, it appears probable that there is a critical dosage which could be given to the middle regions of the thong for the purpose of partially destroying the auxin supply and thus eventually causing the formation of buds at both ends. Further experiments will be carried out to verify this point.

I am indebted to Prof. R. H. Stoughton for the supervision of this work and also to MetropolitanVickers Electrical Co., Ltd., who kindly consented to carry out the X-ray irradiation of the seakale thongs.

Department of Horticulture,

Wm. Plant.

\section{University of Reading.}

'Stoughton, R. H., and Plant, W., NAture, 142, 293 (1938).

2 Plant, W., Annals of Bot., N.S., 4, 607-616 (1940).

${ }^{3}$ Skoog, F., Science, 79, 256 (1934).

\section{Ovarian Damage in Mature Baboons produced by Progesterone and Estradiol Benzoate}

Ir has been repeatedly shown ${ }^{1}$ that the administration of progesterone in amounts of $15 \sim 20 \mathrm{mgm}$. to normal adult baboons in the first part of the cycle (eighth-tenth day) will cause the turgescent perineum to undergo deturgescence, and premature bleeding supervenes within 5-8 days of the last injection. Any quantity of progesterone more than $3 \mathrm{mgm}$. and less than $15 \mathrm{mgm}$. will only cause perineal deturgescence.

Examination of the ovaries of baboons treated in this fashion surprisingly reveals the development in one ovary of one or two follicular cysts which may be four times the size of a normal ovary.

Cystic ovaries therefore have been induced in primates by a hormone other than A.P. or A.P.L. substances.

The administration of a single injection of $0 \cdot 5-5 \cdot 0$ $\mathrm{mgm}$. cestradiol benzoate to baboons in the first part of the cycle will also cause perineal deturgescence which lasts $12-16$ days instead of 5-8 days as after progesterone. The experimental cycle is prolonged by 18 days, that is, menstrual bleeding occurs on the fifty-sixth day instead of the usual thirty-eighth. Both ovaries of such œestrogen-treated baboons show degeneration of the stratum granulosum of all the follicles which contain follicular fluid.

If œstradiol benzoate is given daily to baboons from the eighth day of the cycle, then the perineum continues to rise and may be maintained in a state of turgescence for as long as the injections are continued. The ovaries display massive atresia of follicles and there remain only a few apparently unaffected fluid-containing follicles.

If both œstradiol benzoate ( $1 \mathrm{mgm}$.) and progesterone $(5 \mathrm{mgm}$.) are simultaneously administered 